\title{
Motivation-Related Issues to Learn Different Languages in an Intercultural School
}

\author{
Konstantina Iliopoulou and Areti-Maria Sougari \\ Secondary Sector, Aristotle University of Thessaloniki \\ k.iliopoulou@live.com, asougari@enl.auth.gr
}

\begin{abstract}
This paper reports on the findings of a study involving 98 lower secondary students who receive schooling in a Greek intercultural school, aiming to investigate their motivational orientations towards the learning of Greek as a second language, English as an additional language (which is also a compulsory school subject) and a chosen additional language (i.e. French and German). The study used closed questionnaire items which examined possible varying motivation among the respondents in order to find similarities and/or differences associated with the different target languages when compared with the students' motivation to learn the language of the host country, which is also the medium of instruction. The findings shed light into learners' motivation towards the various languages and offer insight into learners' attitudes towards different foreign languages.
\end{abstract}

\section{Introduction}

Many national language policies around the world promote multilingualism and it is quite common for students to learn a number of foreign languages simultaneously. Educational systems are faced with the challenge to address the needs of the student population while at the same time addressing social, cultural and political demands (UNESCO 2003). A number of fundamental standard-setting instruments have been trying to draw an international agreement on the issue of language and its importance in the educational system. In a number of learning environments, the choice of the language of instruction is the official language of a particular country. Certain educational policies conform to the various declarations and incorporate the languages spoken by the student population in their home environment within the school curriculum. Due to many problems associated with this undertaking, educational

\section{(cc) BY-NC-ND}


policies may dictate the teaching of particular languages which is associated with economic and socio-political principles (Tripolitakis, 2010).

Admittedly, the learning of certain languages may invoke positive, ambivalent, or negative feelings. Even students who come from the same socio-cultural background may respond differently to the various languages incorporated in the school curriculum and subsequently inform their motivational orientations towards the learning of these languages. Few studies have tried to shed light on the learners' attitudes and motivation to learn different target languages and when this was undertaken it was normally attempted within the same community (Clément $\&$ Kruidenier 1983, in the Canadian context; Schmidt and Watanabe 2001, in the Hawaiian context; Dörnyei \& Csizér 2002, in the Hungarian context; Sciriha 2001, in the Maltese context; Shameem 2004, in the Fijian context; and Humphreys \& Spratt 2008, in the Asian context). Furthermore, there is limited research on the effect of the cultural background of immigrant students on their attitudes and motivation to learn different languages (Bernaus et al. 2004 in Spain). The present study reports immigrant students' attitudes and motivation to learn different languages taught in the Greek lower secondary context, while following tuition in an intercultural school, which accounts for great linguistic diversity in the language classroom. Therefore, the aim of the current study was to investigate immigrant students' motivational orientations towards the four languages incorporated in the curriculum: Greek as a second language and medium of instruction, English as an additional language (which is also a compulsory school subject) and a chosen additional language (i.e. French and German).

\section{Background to the Study}

\subsection{Language Attitudes and Motivation}

Early attempts to investigate language attitudes and motivation to learn a second language are associated with the work conducted by Gardner and Lambert $(1959,1972)$, who identified two types of motivational orientations: instrumental and integrative. The former refers to pragmatic reasons for wanting to learn a particular language, whereas the latter reflects a desire to learn a language so as to engage in conversations with the target population. Even though this dichotomy is viewed as an oversimplication of an extremely sophisticated and complex issue and as context-specific, relevant to sociolinguistic contexts similar to the Canadian, a number of studies have based their framework on the idea of the two orientations (Hamphreys and Spratt 2008). 
Extensive research has investigated the underlying motives to learn a second language over the past decades and many studies have investigated the relationship between motivation and the following: achievement (Dörnyei 2001; Gardner 1985; Masgoret \& Gardner 2003; Muñoz \& Tragant 2001), gender-related differences (Carr and Pauwels 2006; Maclntyre et al. 2003), the socio-educational context in which the various studies were carried out (Dörnyei 1990; Gardner 1988; Oxford and Shearin 1994; Warden and Lin 2000).

Notwithstanding the fact that attitudes and motivation bear relevance to the choice of language that students opt for in schools (i.e. should they be given an option), their choice and motivation to learn these languages also relates to the status of languages (Sciriha 2001). In the Hungarian context, survey data, focusing on five target languages and six target language communities were collected with the help of the Language Disposition Questionnaire during three rounds by targeting the same population and by tracking changes over time within a particular population. This study made use of the generalized aspects of L2 motivation and its seven components as identified by Dörnyei, Csizér and Németh (2006): integrativeness, instrumentality, attitudes towards L2 speakers, vitality of the L2 community, cultural interest, milieu and linguistic self-confidence. The results demonstrated a change of the learner dispositions towards learning foreign languages over time, while English had maintained its high status due to the widely acknowledged role in the world.

What is more, even though it seems that students' attitudes towards learning a particular language can be influenced by their ethnic background (Brohy 2001), little research has attempted to highlight learners' motivational orientations towards learning different languages in multicultural classrooms (Bernaus et al 2004; Sougari and Iliopoulou 2013). Therefore, the impetus for the present study is to contribute to the research on immigrant students' attitudes and motivation to learn different foreign languages while attending an intercultural lower secondary school within the Greek educational context.

\subsection{Intercultural Education in Greece}

Immigration influx in Greece has been taking place since the early 1990 s and Greece has become a host for immigrants from eastern and central Europe, coethic 'returnees' and/or their descendants from the former Soviet Republics, Greek Albanians immigrants, others from Third World countries and a few Greek emigrants returning to Greece (Triantafyllidou and Gropas 2007, 2009). It is quite apparent that this immigration influx has altered the characteristics of the population by resulting in changes on the social, economic, ethnic, educational, religious and racial level. The societal diversity has also permeated the classroom setting and the new reality called for changes at the education sector. After all, 
for the purposes of national cohesion and national consciousness, it is important to integrate the migrant population in all aspects of public life.

In response to growing immigration, initially reception classes were set up so as to cater for the immigrants' cultural, educational and linguistic needs. Various pedagogical orientations have replaced previous structures of the educational system. The development of intercultural education has marked the establishment of a new category of schools, which host reception classes for students with limited or no knowledge of Greek (Law 2416/96; Paleologou 2004) Since 1996, out of a total 26 intercultural schools across Greece, thirteen are primary schools, nine are lower secondary schools and four are upper secondary schools. A school can be identified as an intercultural one when $45 \%$ of its student population is of non-Greek origin. It is worthwhile mentioning that the student body of each intercultural school may differ substantially in terms of the students' country of origin. The diminishing number of upper secondary schools available can be associated with the immigrant students' low interest in pursuing further education beyond the compulsory level.

Even though these schools follow the ordinary curriculum, there is no need to cover the curriculum in its entirety. Special emphasis is placed on learning the Greek language as well as the other languages that are part of the compulsory curriculum (i.e. English and a choice between French or German). Greek is the medium of instruction, but English is also used in instances that need further clarification.

\section{The Present Study}

The dearth of studies on immigrant students' motivation to learn different languages in the Greek educational context have given rise to the present study. To be more specific, this study investigates the motivation to learn different foreign languages among immigrant students who follow instruction in a Greek lower secondary intercultural school. Therefore, the focus is on their motivation towards the learning of Greek as a second language, English as an additional language (which is also a compulsory school subject) and a chosen additional language (i.e. French and German). It becomes pertinent to address immigrant students' attitudes in order to unravel the nature of the appeal exercised by the different languages.

\subsection{The Respondents}

The current study was carried out on a sample of 98 (52\% were male students, whereas $48 \%$ were female) immigrant lower secondary students at a Greek 
intercultural school, situated in Thessaloniki. The breakdown of the sample in the three grades was conducted as follows: $1^{\text {st }}$ grade: $29.6 \%, 2^{\text {nd }}$ grade: $35.7 \%$ and $3^{\text {rd }}$ grade: $34.7 \%$ of student population. With particular reference to the distribution in the class for the subject of Greek, the following placement pattern appears: $1^{\text {st }}$ grade beginners: $37.9 \%$, intermediate: $31 \%$, advanced: $31 \%$; $2^{\text {nd }}$ grade beginners: $22.9 \%$, intermediate: $40 \%$, advanced: $37.1 \%$; and $3^{\text {rd }}$ grade beginners: $29.4 \%$, intermediate: $26.5 \%$, advanced: $44.1 \%$. According to the curriculum, the students, apart from Greek and English, had opted for a chosen additional language as follows: $66.3 \%(\mathrm{~N}=65)$ attended German and $33.7 \%$ $(\mathrm{N}=33)$ attended French. Due to the influx of immigrants to Greece, this particular school accommodates newcomers who have either recently migrated to Greece or those who had previously attended an intercultural primary school. Thus, in this study the students come from various countries and different linguistic backgrounds: $22.4 \%$ come from China, $18.4 \%$ come from Albania, $16.3 \%$ come from Georgia, 16.3\% come from Russia, 16.3\% come from Afghanistan, 5.1\% come from FYROM, and $5.1 \%$ come from various countries.

\subsection{Instrumentation}

For the purposes of the present study, quantitative and qualitative data were drawn in an attempt to assess students' attitudes and motivation to learn different foreign languages in a Greek intercultural school. The respondents were granted their anonymity throughout the whole procedure. Quantitative data were gathered with the help of a questionnaire, which is an adaptation of the one used by Dörnyei and Clement (2001) in the Hungarian context. The wording of certain items was simplified, certain items were dropped and others were added; these changes were deemed necessary in order to suit the Greek context and to match the respondents' proficiency level.

Two versions of the questionnaire were made available: one in Greek and one in English. The respondents were given the option to report their views on the items in question in either one of the two languages. It is worthwhile mentioning that the majority of the respondents opted for the Greek version and explanations were provided where necessary depending on the learners' proficiency level. In the case of beginners, the questionnaire was provided in English and further clarifications were given if needed.

The questionnaire consisted of three parts: part 1 elicited some demographic information such as gender, age, country of origin, language(s) spoken in their home environment and their personal assessment of their command in the languages in question. The formation of their profile was intentionally placed in the front part of the questionnaire so as to introduce respondents to the rationale of the questionnaire; part 2 drew the respondents' views about the 
learning of particular languages (i.e. Greek, English, French or German) as well as their attitudes towards the target speech community of each language, and part 3 elicited the students' stance towards language learning. Due to our attempt to partially replicate the Hungarian study, the seven motivational dimensions (i.e. integrativeness, instrumentality, attitudes towards L2 speakers, vitality, cultural interest, milieu and linguistic self-confidence) identified by Dörnyei and Clement (2001) and Dörnyei and Cziser (2002) were retained.

Qualitative data were drawn with the help of nine follow-up semi-structured interviews (i.e. three students of each grade and one of each proficiency level, who came from different countries, were interviewed). The interviews highlighted areas that needed further elucidation, i.e. what informs the participants' attitudes to learning the languages included in the curriculum. The findings that were raised in the qualitative part are beyond the scope of the present paper and appear in another paper (Sougari and Iliopoulou 2013).

\subsection{Data Analysis}

With regard to the analysis of the sample, the computation of frequencies and the implementation of the Wilcoxon signed-ranks test were conducted. The Wilcoxon signed-ranks test was used to assess the magnitude of the difference in the sample's answers; to be more specific, the respondents' perception about Greek is compared to each one of the other foreign languages incorporated in the curriculum. The choice of this particular test is based on the nature of the questionnaire, which elicited answers to items that appeared in a 5-point Likert scale; to be more specific, in part 2: 1 was 'very much' and 5 was 'not at all', whereas in part 3: 1 was 'strongly disagree' and 5 was 'strongly agree'. Cronbach $\alpha$ was used in order to draw the internal reliability coefficients for each target language and was calculated separately for each language. It is worthwhile mentioning that in the case of answers to questions pertaining to attitudes towards the learning of French and German only the answers of those learners who were attending such courses were accounted for. The significance level was set at $p<.05$.

\subsection{Results and Discussion}

With particular reference to the 27 items that were incorporated in the questionnaire, the motivational dimensions for which the Cronbach $\alpha$ coefficient was calculated individually for each language can be found below:

- Integrativeness: three constituent items pertaining to the respondents' desire to integratein the target speech community were used; these 
items drew on the extent to which: (1) the respondents liked the target languages; (2) they felt that it was important to know these language in order to become acquainted with the culture of the respective target group; and (3) they wanted to become similar to the people who spoke these languages (Greek: $\alpha=0.86$, English: $\alpha=0.91$, German: $\alpha=0.56$, French: $\alpha=0.52$ ).

- Instrumentality: four items assessed the students' perceptions about the role of the various languages in their lives. These items were as follows: how much they thought knowing these languages would help: (1) their future career; (2) to become a more knowledgeable person; and (3) when traveling abroad in the future. A fourth item enquired about how important they thought these languages were in the world (4) (Greek: $\alpha=0.81$, English: $\alpha=0.71$, German: $\alpha=0.90$, French: $\alpha=0.81$ ).

- Attitudes towards L2 speakers: the three items were used to evaluate the students' affective reactions toward the target speech community. These items asked the respondents to state: (1) how much they would like to travel to these countries; (2) how much they liked meeting people from these countries; and (3) how much they liked the people who live in these countries (Greece: $\alpha=0.84$, English/ US: $\alpha=0.97$, English/UK: $\alpha=0.92$, Germany: $\alpha=0.85$, French: $\alpha=0.84$ ).

- Vitality: two items assessed students' views about the role of these countries in the modern world. In this case, the respondents were expected to respond to (1) whether they believed that these countries were rich and developed, and (2) whether these countries played an important role in the world (Greece: $\alpha=0.98$, English/US: $\alpha=0.95$, English/UK: $\alpha=0.88$, Germany: $\alpha=0.69$, French: $\alpha=0.72$ ).

- Cultural interest: four items measured students' interest in learning these languages so as to expand their knowledge about culturalrelated issues. These items drew answers on how much the respondents liked (1) the films, (2) the TV programmes, (3) the magazines made in these countries, and (4) the music of these countries (Greece: $\alpha=0.64$, English/US: $\alpha=0.83$, English/UK: $\alpha=0.83$, Germany: $\alpha=0.39$, French: $\alpha=0.43$ )

- Milieu: two items were used to evaluate the influence exerted on the individual learners by their environment to learn foreign languages. Towards this direction, the respondents were asked to state (1) whether foreign languages were an important school subject, and (2) whether their relatives and friends considered foreign languages important school subjects $(\alpha=0.44)$.

- Linguistic self-confidence: two items asked respondents to assess (1) the prospect of a successful language learning outcome, and (2) the effort needed to learn a foreign language $(\alpha=0.67)$ 
It should be noted that not all the items of the questionnaires were used in the making of the motivational dimensions due to the lack of connection with the motivation to learn any of these languages. As can be seen, most of the motivational dimensions mentioned above attained good reliability. The rather low reliability of certain items can be associated with the small number of respondents who have responded to the items connected with cultural-related issues and who have limited or no relevant cultural experience. The present paper will present the findings that reflect the respondents' first three motivational facets, namely those of integrativeness, instrumentality and attitudes towards $L 2$ speakers.

\subsubsection{Integrativeness}

With particular reference to the items that fall under integrativeness, it becomes apparent that the respondents were quite neutrally disposed towards all the languages incorporated in their curriculum. Table 1 presents descriptive statistics and the Wilcoxon singed ranks results comparing each target language with Greek, which is both the medium of instruction and a school subject. However, English seems to be more endorsed than the other two chosen languages, reflecting the importance of gaining knowledge about culture-related issues tied with the English-speaking world.

Table 1.

Learners' integrativeness

\begin{tabular}{|l|c|c|c|c|}
\hline & $\begin{array}{c}\text { Greek } \\
\text { M* }\end{array}$ & $\begin{array}{c}\text { English } \\
\text { M }\end{array}$ & $\begin{array}{c}\text { French } \\
\text { M }\end{array}$ & $\begin{array}{c}\text { German } \\
\text { M }\end{array}$ \\
\hline $\begin{array}{l}\text { Liking these languages } \\
\text { Greek vs English: } N=54, z=-1,182, p>.05 \\
\text { Greek vs French: } N=18, z=-342, p>.05 \\
\text { Greek vs German: } N=45, z=-1,008, p>.05\end{array}$ & 2.60 & 2.50 & 2.76 & 2.71 \\
\hline $\begin{array}{l}\text { Importance of learning theses languages in order } \\
\text { to learn about the culture of its speakers } \\
\text { Greek vs English: } N=47, z=-566, p>.05 \\
\text { Greek vs French: } N=29, z=-3,792, p<.001\end{array}$ & 2.38 & 2.34 & 3.21 & 2.92 \\
Greek vs German: $N=55, z=-4,417, p<.001$ & & & & \\
\hline $\begin{array}{l}\text { Wanting to become similar to the people who } \\
\text { speak these languages } \\
\text { Greek vs English: } N=58, z=-1,886, p=.059 \\
\text { Greek vs French: } N=29, z=-4,801, p<.001\end{array}$ & 2.48 & 2.32 & 4.12 & 4.11 \\
Greek vs German: $N=51, z=-6,368, p<.001$ & & & & \\
\hline
\end{tabular}

$* M=$ mean, 1 : very much, 5 : not at all

The respondents felt that it is more important to learn either Greek or English in order to draw information about the respective culture, manifesting thus their preference either about the culture of the host country, i.e. Greece or about the English one. The results also indicated the similar feelings held by the 
respondents towards assimilating in the Greek and English-speaking community. However, when contrasting the attitudes towards the Greek with the German or French speaking community, it becomes apparent that the respondents held more positive feelings for the Greek one. After all, all the respondents had arrived in Greece either on their own or with their families; this issue is quite important as at some point a decision was made in relation to the selection of a preferred destination.

\subsubsection{Instrumentality}

The results showed no significant interaction between Greek and English for all of the motivational dimensions under instrumentality, except for the important role that English plays in the worldwide community. The high importance placed on the role of English reflects the participants' acknowledgement of the high status that English has and the influence exercised on all facets of economy, internet, relationships among countries and so on. Furthermore, English is also acknowledged as being a necessary tool for communication purposes when traveling, even though no significant results were rendered when compared to Greek; such a finding can very well reflect the respondents' desire to travel within Greece. However, the driving force may not be so much due to seeking a destination for leisure, enjoyment and discovery, but due to the need to seek future employment. Thus, English can serve as a means of communication with people from other countries, whereas Greek can be utilized and prove useful only within the Greek borders. Table 3 illustrates the results connected with instrumentality.

Table 2.

Learners' instrumentality

\begin{tabular}{|l|c|c|c|c|}
\hline & $\begin{array}{c}\text { Greek } \\
\text { M* }\end{array}$ & $\begin{array}{c}\text { English } \\
\text { M }\end{array}$ & $\begin{array}{c}\text { French } \\
\text { M }\end{array}$ & $\begin{array}{c}\text { German } \\
\text { M }\end{array}$ \\
\hline $\begin{array}{l}\text { Helpful in getting to know new things } \\
\text { Greek vs English: } N=54, z=-511, p>.05 \\
\text { Greek vs French: } N=20, z=-3,508, p<.001 \\
\text { Greek vs German: } N=48, z=-4,045, p<.001\end{array}$ & 2.53 & 2.49 & 3.30 & 3.09 \\
\hline $\begin{array}{l}\text { Importance in the world these days } \\
\text { Greek vs English: } N=73, z=-7,541, p<.001 \\
\text { Greek vs French: } N=21, z=-1,843, p>.05 \\
\text { Greek vs German: } N=46, z=-2,835, p<.01\end{array}$ & 2.57 & 1.49 & 2.97 & 2.92 \\
\hline $\begin{array}{l}\text { Helpful when traveling } \\
\text { Greek vs English: } N=41, z=-1,540, p>.05\end{array}$ & 2.40 & 2.29 & 3.33 & 2.97 \\
$\begin{array}{l}\text { Greek vs French: } N=18, z=-3,318, p<.01 \\
\text { Greek vs German: } N=44, z=-4,046, p<.001\end{array}$ & & & & \\
\hline $\begin{array}{l}\text { Helpful in finding } a \text { job } \\
\text { Greek vs English: } N=58, z=-1,471, p>.05\end{array}$ & 1.91 & 2.04 & 3.31 & 2.78 \\
$\begin{array}{l}\text { Greek vs French: } N=21, z=-3,959, p<.001 \\
\text { Greek vs German: } N=44, z=-5,460, p<.001\end{array}$ & & & & \\
\hline
\end{tabular}

$\therefore M=$ mean, 1 : very much, 5 : not at all 
When it comes to finding a job, the respondents feel that both Greek and English can prove quite useful. The two chosen additional languages (i.e. French and German) are not considered important school subjects to the extent that other subjects are. It seems that due to the importance of particular languages in the world reality, certain languages are preferred over others (i.e. English), and the respondents who learn French also contemplate quite similar roles for both Greek and French in the global village.

\subsubsection{Attitudes towards L2 Speakers}

In terms of attitudes towards the target $L 2$ speakers of the different countries, it becomes apparent that overall the respondents held more positive attitudes towards Greek people (see Table 3). In descending order, the rating of the other target populations was: English speaking people, German and French. However, with particular reference to the respondents' desire to travel, even though no significant differences emerged between Greek and any of the two English target communities, such a desire was much stronger in the case of Greece than it was for France or Germany.

Table 3.

Learners' attitudes towards L2 speakers

\begin{tabular}{|c|c|c|c|c|c|c|}
\hline & & $\begin{array}{c}\text { Greece } \\
M^{*}\end{array}$ & $\begin{array}{c}\text { England } \\
M\end{array}$ & $\begin{array}{l}\text { US } \\
\text { M }\end{array}$ & $\begin{array}{c}\text { France } \\
\text { M }\end{array}$ & $\begin{array}{c}\text { Germany } \\
M\end{array}$ \\
\hline $\begin{array}{l}\text { Desire to travel } \\
\text { Greece vs England: } \\
\text { Greece vs US: } \\
\text { Greece vs France: } \\
\text { Greece vs Germany: }\end{array}$ & $\begin{array}{l}N=63, z=-838, p>.05 \\
N=57, z=-486, p>.05 \\
N=29, z=-4,186, p<.001 \\
N=46, z=-5,784, p<.001\end{array}$ & 1.52 & 1.59 & 1.56 & 2.48 & 2.40 \\
\hline $\begin{array}{l}\text { Desire to meet peopl } \\
\text { Greece vs England: } \\
\text { Greece vs US: } \\
\text { Greece vs France: } \\
\text { Greece vs Germany: }\end{array}$ & $\begin{array}{l}\text { Le from these countries } \\
N=58, z=-2,101, p<.05 \\
N=56, z=-2,795, p<.01 \\
N=29, z=-4,441, p<.001 \\
N=47, z=-6,227, p<.001\end{array}$ & 1.30 & 1.46 & 1.52 & 2.33 & 2.29 \\
\hline $\begin{array}{l}\text { Liking these people } \\
\text { Greece vs England: } \\
\text { Greece vs US: } \\
\text { Greece vs France: } \\
\text { Greece vs Germany: }\end{array}$ & $\begin{array}{l}N=59, z=-1,697, p>.05 \\
N=55, z=-1,499, p>.05 \\
N=26, z=-3,810, p<.001 \\
N=47, z=-5,443, p<.001\end{array}$ & 1.42 & 1.56 & 1.54 & 2.56 & 2.48 \\
\hline
\end{tabular}

$\approx M=$ mean, 1: very much, 5: not at all

Due to residing in Greece, the respondents were more positively predisposed towards Greek people and seemed more inclined to meet Greek people, which can be a sign of striving to become active members in the host country. Overall the respondents were quite positive toward English-speaking people and professed to like the people coming from these countries. The familiarity with 
the language, the perceived usefulness of this language in the world associated with their future quest for a job explains the favourable attitude toward Englishspeaking people.

\subsubsection{Assessing the Motivational Dimensions}

Table 4 presents a synopsis of the main findings by looking at the motivational dimensions. More particularly, the mean of the three motivational dimensions was computed for each of the four languages incorporated in the curriculum and the five target communities. The motivational dimensions are presented in ascending order.

Table 4.

Ranking of motivational dimensions for the four languages: Greek, English, French and German

\begin{tabular}{|c|c|c|c|c|}
\hline Scale point & Greek & English & French & German \\
\hline $1.0-1.49$ & $\begin{array}{l}\text { Attitudes towards } \\
\text { L2 speakers } \\
M=1.41, S D=0.49\end{array}$ & & & \\
\hline $1.5-1.9$ & & $\begin{array}{l}\text { Attitudes towards L2 } \\
\text { speakers (UK) } \\
M=1.54, S D=0.52 \\
\text { Attitudes towards L2 } \\
\text { speakers (US) } \\
M=1.54, S D=0.55\end{array}$ & & \\
\hline $2.0-2.4$ & $\begin{array}{l}\text { Instrumentality } \\
M=2.35, S D=0.62 \\
\text { Integrativeness } \\
M=2.49, S D=0.70\end{array}$ & $\begin{array}{l}\text { Instrumentality } \\
M=2.08, S D=0.56 \\
\text { Integrativeness } \\
M=2.38, S D=0.78\end{array}$ & $\begin{array}{l}\text { Attitudes towards } \\
\mathrm{L} 2 \text { speakers } \\
M=2.46, S D=0.64\end{array}$ & $\begin{array}{l}\text { Attitudes towards } \mathrm{L} 2 \\
\text { speakers } \\
M=2.39, \mathrm{SD}=0.70\end{array}$ \\
\hline \multicolumn{5}{|l|}{$2.5-2.9$} \\
\hline $3.0-3.4$ & & & $\begin{array}{l}\text { Instrumentality } \\
M=3.28, S D=0.59 \\
\text { Integrativeness } \\
M=3.36, S D=0.69\end{array}$ & $\begin{array}{l}\text { Instrumentality } \\
M=3.23, S D=0.74 \\
\text { Integrativeness } \\
M=3.25, S D=0.74\end{array}$ \\
\hline
\end{tabular}

$\mathrm{M}=$ mean, $\mathrm{SD}=$ standard deviation

Across the four languages, the order in which the three motivational dimensions appear is the same, following the pattern of: attitudes towards L2 speakers, instrumentality and integrativeness. What seems to present a distinct pattern is the respondents' preference for a particular target population in the following order: Greek, English, German and finally French. All the means, with the exception of those for instrumentality and integrativeness for French and German, fall under the 2.5 point of the Likert scale. As can be seen, the two dimensions of instrumentality and integrativeness for English are higher than those for Greek. 
It seems that the positive attitudes towards the target population, along with the perceived usefulness of each language, lead to subsequent desire to integrate in the respective target speech community.

\section{Conclusion}

The present study investigated the motivation to learn different foreign languages among immigrant students who followed instruction in a Greek lower secondary intercultural school. The findings suggest that students hold more positive attitudes towards learning Greek and English; thus they are more motivated to learn these two languages. The driving force for learning these two languages seems quite distinct. Greece has been their own or their parents' chosen destination and thus they want to learn the language to increase prospects of a better job but also to engage in communication exchanges with the members of the target speech community. However, as it became transparent in the follow-up interviews (Sougari and Iliopoulou 2013), English is perceived as a tool for communication with speakers in the worldwide community and thus not confined within the borders of one country.

In the present study, the findings showed that the students hold positive attitudes towards Greek people, more so than towards the other target groups. However, it should be noted that in an earlier study conducted in the same intercultural school, where immigrant students' attitudes towards Greek were drawn in order to form these students' motivational profile, it was concluded that overall the students were negatively predisposed towards the Greek speech community (Sougari and Iliopoulou 2012). This discrepancy in the findings can be explained by the fact that the previous study was conducted before the breaking news of the economic crisis in Greece. The change in the students' attitudes can be associated with their belief that it would be easier to integrate in the Greek community, while the country is facing financial and societal problems, probably similar to the ones experienced in their home country. Furthermore, the structure of the questionnaire which was presented in the form of a grid where the respondents were expected to record their answers about the four languages and the five speaking communities may have led to unintended comparisons among the four languages and the five speaking communities.

At present, the students want to come into contact with the people of the host country, rather than be alienated; at the same time they want to retain their identity. The fact, that the majority of the participants had recently arrived in the host country rather than being born and raised, plays a significant role in the formation of strong feelings of preserving their identity. However, the instrumental dimension across the four languages presented quite a variation; 
the perceived usefulness of English and Greek is the driving force to learn these languages. The pragmatic benefits of knowing these languages are connected with the prospects of finding a job either in Greece or elsewhere. With regard to the two chosen additional languages, the greater familiarity with the members of the host community (i.e. Greek people) and native speakers of English through their exposure to television series, music, reading material, etc. may have played a role in the higher disposition across all the motivational dimensions.

The information drawn from this study can prove helpful to educational policy makers, materials developers and teachers in particular. After all, teachers come into close contact with their students and ought to cater for individual needs more effectively. However, attempts at all levels should be geared towards the integration of the immigrant student population into public life. 


\section{References}

Bernaus, M., A.-M. Masgoret, R.C. Gardner and E. Reyes. 2004. Motivation and attitudes towards learning languages in multicultural classrooms. International Journal of Multilingualism 1(2): 75-88.

Brohy, C. 2001. Generic and/or specific advantages of bilingualism in a dynamic plurilingual situation: The case of French as official L3 in the school of Samedan (Switzerland). International Journal of Bilingual Education and Bilingualism 4(1): 38-49.

Carr, J. and A. Pauwels. 2006. Boys and foreign language learning: real boys don't do languages. Palgrave: Macmillan.

Clément, R. and B. Kruidenier. 1983. Orientations in second language acquisition: The effects of ethnicity, milieu, and target language on their emergence. Language Learning 33(3): 273-291.

Dörnyei, Z. 1990. Conceptualizing motivation in foreign language learning. Language Learning 40(1): 46-78.

Dörnyei, Z. 2001. Motivational Strategies in the Language Classroom. Cambridge: Cambridge University Press.

Dörnyei, Z. and R. Clément. 2001. Motivational characteristics of learning different target languages: results of a nationwide survey. In Z. Dörnyei and R. Schmidt (eds.), Motivation and Second Language Acquisition. Honolulu: University of Hawaii, 399-432.

Dörnyei, Z. and K. Csizér. 2002. Some dynamics of language attitudes and motivation: results of a nationwide survey. Applied Linguistics 23(4): 421-462. 
Dörnyei, Z., K. Csizér and N. Németh. 2006. Motivation, Language Attitudes and Globalisation: A Hungarian Perspective. Clevendon: Multilingual Matters.

Dörnyei, Z. and R. Schmidt (eds.). 2001. Motivation and Second Language Acquisition. Honolulu: University of Hawaii.

Gardner, R.C. 1985. Social Psychology and Second Language Learning: The Role of Attitudes and Motivation. London: Edward Arnold.

Gardner, R.C. 1988. The socio-educational model of second language learning: assumptions, findings and issues. Language Learning 38(1): 101-126.

Gardner, R.C. and W. Lambert. 1959. Motivational Variables in Second Language Acquisition. Canadian Journal of Psychology 13(4): 266-272.

Gardner, R.C. and W. Lambert. 1972. Attitudes and Motivation in Second Language Learning. Rowley, MA: Newbury House.

Humphreys, G. and M. Spratt. 2008. Many languages, many motivations: a study of Hong Kong students' motivation to learn different target languages. System 36(2): 313-335.

Laine, E. 1995. Learning Second National Languages: A Research Report. Frankfurt: Peter Lang.

MacIntyre, P., S.C. Baker, R. Clement and L. Donovan. 2003. Talking in order to learn: willingness to communicate and intensive language programs. Canadian Modern Language Review 59(4): 589-607.

Masgoret, A.-M. and R.C. Gardner. 2003. Attitudes, motivation and second language learning: A meta-analysis of studies conducted by Gardner and associates. Language Learning 53(1): 123-163.

Muñoz, C. and E. Tragant. 2001. Motivation and attitudes towards L2: Some effects of age and instruction. EUROSLA Yearbook 1: 211-224.

Oxford, R.L. and J. Shearin. 1994. Language learning motivation: expanding the theoretical framework. Modern Language Journal 78(1): 12-28.

Paleologou, N. 2004. Intercultural education and practice in Greece: needs bilingual intercultural programmes. Intercultural Education 15(3): 317- 329. 
Sciriha, L. 2001. Trilingualism in Malta: Social and educational perspectives. International Journal of Bilingual Education and Bilingualism 4(1): 23-37.

Schmidt, R. and Y. Watanabe. 2001. Motivation, strategy use, and pedagogical preferences in foreign language learning. In Z. Dörnyei and R. Schmidt (eds.) Motivation and Second Language Acquisition. Honolulu: University of Hawaii, 313-359.

Shameem, N. 2004. Language attitudes in multilingual primary schools in Fiji. Language Culture and Curriculum 17(2): 154-172.

Sougari, A.-M. and K. Iliopoulou. 2012. Investigating learners' attitudes towards Greek as a second language in an intercultural school. In Z. Gavriilidou, A. Efthymiou, E. Thomadaki \& P. Kambakis-Vougiouklis (eds), Selected Papers of the 10th International Conference of Greek Linguistics. Komotini/Greece: Democritus University of Thrace, 531-538.

Sougari, A.-M. and K. Iliopoulou. 2013. Giving voice to students' views on various languages in a multicultural classroom setting. In Y. Bayyurt and S. Akcan (eds.), Proceedings of the Fifth International Conference of English as a Lingua Franca. Bogaziçi University, 414-424.

Triandafyllidou, A. and R. Gropas. 2007. Greek Education Policy and the Challenge of Migration: An Intercultural View of Assimilation. Policy brief for the EMILIE project A European Approach to Multicultural Citizenship: Legal, Political and Educational Challenges. European Commission Research.

Triandafyllidou, A. and R. Gropas. 2009. Migration, Identity and Citizenship: Approaches for Addressing Cultural Diversity in Greece. Report prepared for the EMILIE project A European Approach to Multicultural Citizenship: Legal, Political and Educational Challenges. European Commission Research.

Tripolitakis, K. 2010. Network Governance and Public Policy: Language Planning and Language Policy in Australia and Greece within a Globalising Context (19702005). Unpublished PhD dissertation. RMIT University, Melbourne.

UNESCO. 2003. Education is a Multilingual World. UNESCO Education Position Paper. Paris: United Nations.

Warden, C.A. and H.J. Lin. 2000. Existence of integrative motivation in an Asian EFL setting. Foreign Language Annals 33(5): 535-547. 